\title{
Analyzing the moderating effects of respondent type and experience on the fuel efficiency improvement in air transport using structural equation modeling
}

\author{
Vedant Singh $^{1} \cdot$ Somesh K. Sharma ${ }^{2}$
}

Received: 11 February 2016 / Accepted: 19 April 2016/Published online: 30 April 2016

(C) The Author(s) 2016. This article is published with open access at SpringerLink.com

\begin{abstract}
Introduction The limited nature of oil, and hence aviation fuel is increasingly becoming a restraining factor for the air transport industry. Also, fuel efficiency is crucial for commercial air transport as fuel is one of the most costly operating parameters for an airline.

Methodology This study employs structural equation modelling (SEM) approach to identify key dimensions influencing fuel efficiency in air transport (FEAT) and to explore the correlational relationships among constructs from the perspectives of fuel efficiency improvement. Self-administered questionnaires were used to collect data from 375 aviation experts. Correlation, multi-group moderation analysis, and interaction using structural equation model were used to analyses these data.

Results The results and applications of SEM evolve a variety of findings; aircraft technology \& design, aviation operations infrastructure, socioeconomic \& political measures, and alternative fuels $\&$ fuel properties, and aviation infrastructure are proved to be the five key influential dimensions affecting the fuel efficiency and have a positive effect on the FEAT. In addition, the moderating effect of industry type and experience were established. The results also showed that no significant interaction effect between dimensions of FEAT.
\end{abstract}

Vedant Singh

er.vedu@gmail.com

1 Department of Mechanical Engineering, Abhilashi University, Chail-Chowk, Mandi 175028, HP, India

2 Department of Mechanical Engineering, National Institute of Technology, Anu, Hamirpur 177005, HP, India
Conclusions The findings of this research can provide air transport valuable information for designing appropriate strategy for fuel efficiency improvement.

Keywords Fuel efficiency in air transport (FEAT) . Multi-group moderation, Structural equation modelling (SEM) - Environmental impact

\section{Introduction}

The limited nature of oil, and hence aviation fuel is increasingly becoming a restraining factor for the air transport industry. Now, airlines are more attentive than ever to raise fuel efficiency due to rising fuel prices and competition among them [20, 36]. According to the projections of Penner [63] the global passenger air traffic, as measured in revenue passenger $\mathrm{km}$, is estimated to grow by about $5 \%$ per year between 1990 and 2015, whereas total aviation fuel consumption, including passenger, freight, and military is projected to increase by $3 \%$ per year. In addition, the fuel consumption of air transport industry has increased at a rate of more than $6 \%$ over the previous 10 years, although, fuel production has developed slowly, increasing at less than $6 \%$ over the same period $[20,53]$. Also, the mean price of jet fuel has increased over the previous 10 years, which was above $\$ 120$ a barrel $[36,53]$. The growing demand of jet fuel and high price will force air transport to improve fuel efficiency. Therefore, airlines are adopting fuel efficient aircrafts, modifying operating practices, and implementing the socioeconomic \& policy measures to improve the fuel efficiency of airlines [13, 83]. The International Air Transport Association (IATA) seeks to raise fuel efficiency across the air transport industry by $1.5 \%$ per annum up to 2020 [37], while the International Civil Aviation Organization (ICAO) is attempting for a $2 \%$ per 
annum improvement up to 2050 [38]. An improved fuel efficiency of airliners, and the consequent lower carbon emission, will reduce the operating cost of an airline along with environmental impact [62].

Fuel efficiency in air transport (FEAT) can be defined as ratio of fuel consumed in liters to revenue tonne kilometer (RTK) [4, 13, 51]. Fuel efficiency of transport aircrafts mainly depends upon two main factors i.e., technology $\&$ design, and aircrafts operations $[4,51]$. Further, aircraft technology \& design depends upon the engine efficiency, aerodynamic efficiency, and structural efficiency, while the aircraft operations relies on ground efficiencies, and airborne efficiencies [4, 73, 74]. In case of aircraft technology \& design, aerodynamic features such as blended wing body (BWB), flying wing, higher aspect ratios, and engines with higher bypass ratios are installed on modern jets to improve the fuel efficiency [1]. Aviation operations contain air traffic management procedures such as performance-based navigation, continuous descent approaches, reduced vertical separation minimum (RVSM) and various air traffic flow management systems, beside improved aircraft operating techniques $[13,26]$.

For the previous few years, existing literature related to estimating air transport fuel efficiency have been limited. Inside the range of air transport fuel efficiency literature, Lee et al. [51] analyzed the relationship between aircraft fuel efficiency and cost, and estimated the aviation emissions reduction potential based on analytical and statistical models. Babikian et al. [4] compared the fuel efficiency of different aircraft types, and emphasized that differences in fuel efficiency could be described largely by differences in aircraft operations. Peeters et al. [62] analyzed the fuel efficiency of commercial aircraft since their initiation in the 1930s, and results showed that the last piston-powered aircrafts were at least twice as fuel-efficient as the first jet-powered aircraft. Williams (2007) highlighted the engineering options for the improvement in aircraft fuel efficiency, and these options had included the changes to airframes, engines, avionics, air traffic control systems, airspace design, and improved market based measures. Morrell [56] investigated the potential for greater fuel efficiency by utilizing larger aircraft and different operational practices. Lee [50]; Lee and Mo [52] have presented the key technologies and policy issues for the induction of energy efficient, environmentally friendly innovations in aircraft systems. Zou et al. [83] used ratio based, deterministic and stochastic frontier approaches to investigate fuel efficiency of transport aircrafts, and the results showed that potential cost savings of airlines. Singh and Sharma [74] explored the aircraft technology, operations, alternative fuels, socio-economic measures, and infrastructural factors for fuel efficiency improvement. Chandra et al. [13] compared fuel efficiencies of selected airlines around the globe, and results found that, the average fuel efficiency of the airlines reported was is $0.4 \mathrm{~L} /$ RTK (revenue tonne kilometer), respectively. Also, this study has investigated the variances in fuel efficiency among airlines from different regions. Li et al. [53] employed the virtual frontier dynamic range adjusted measure to estimate the energy efficiency of 22 airlines during the period of 2008-2012, and the results showed that the aggregate airline energy efficiency consistently increased from 2008 to 2012. Baklacioglu [5] employed a genetic algorithm-optimized neural network topology to predict the fuel flow-rate of a transport aircraft using real flight data, and results showed that the saving in fuel energy, and reducing flight costs.

While all these studies have evaluated the fuel efficiency of different airlines or aircrafts, a comprehensive examination of the relationship between fuel efficiency and its factors, has not been seen in the literature. Only the study of Singh and Sharma [73] analyzed the relationship between fuel efficiency and its factors using structural equation modelling (SEM). However, this study has not analyzed relationships between depend and independent factors of fuel efficiency. Also, moderating effect of industry type respondents and experience, and interaction effect were not discussed in the study of Singh and Sharma [73]. In this study, SEM approach using moderating and interaction effect is proposed to evaluate the relationships between the factors of fuel efficiency. Moreover, SEM has drawn the attention of many researchers as a commonly adopted technique used to examine data about many airline disciplines including passenger loyalty [3], passenger's overall satisfaction with an airport [6], a comprehensive relationship marketing model [15], low cost carrier travelers [18], airline performance [42], airline service quality [48, 75], fuel consumption optimization [73], cabin safety [14, 34], customer loyalty $[22,54]$, job satisfaction $[17,57,81]$ and carbon offset scheme [16].

Therefore, the aims of this study are to explore the holistic relationships among the factors of FEAT, and to examine their effects using multigroup moderation and interaction. To achieve these goals, the critical factors related to fuel efficiency were extracted based on literature reviews, and a questionnaire was constructed for the assessment of FEAT. Self administrated surveys of 375 experts of aviation were performed using the questionnaires to evaluate fuel efficiency perceptions in air transport. Based on the survey results, the conceptual fuel efficiency model was tested using structural equation modeling. In the time of rising fuel prices and mounting environmental concerns, the FEAT model could help us to frame future strategies to improve fuel efficiency of air transport industry.

Following this introduction, Section 2 presents the hypothesized relationships, leading to the development of the research model. Then, Section 3 provides the instrument development, measuring instrument, and techniques of data analysis adopted in this study. Section 4 presents the results of the research study and discuss findings of factor analysis and SEM. Finally, the conclusions and implications are provided in Section 5. 


\section{Hypotheses and research model}

\subsection{Hypotheses}

Based on a review of existing literature on FEAT, five key factors that have direct effects on fuel efficiency improvement are identified as aircraft technology \& design (ATD), aviation operations (AO), socioeconomic \& policy measures (SEP), alternative fuels \& their properties (AFP), and aviation infrastructure (AI) [4, 26, 50-52, 62, 73, 74]. Our hypotheses include five dimensions namely: ATD, AO, SEP, AFP, and AI. The detailed theoretical basis of the hypotheses, and observed variables will be analyzed in the following section.

\subsubsection{Aircraft technology \& design}

ATD is an important dependent factor related to the fuel efficiency. According Williams (2007); Parker [61]; Graham et al. [24] and Miyoshi and Ibáñez [55] the technological advancement has resulted in a positive trend of fuel efficiency. ATD was measured from engine efficiencies, aerodynamic efficiencies, and structural efficiencies [4, 51]. Engine efficiencies were expressed in term of engine thrust specific fuel consumption (TSFC), lower value of TSFC result in better fuel efficiency $[4,25]$. Aerodynamic efficiencies were evaluated in term of lift/drag (L/D) ratio [74]; higher value of lift/drag ratio can result in improved fuel efficiency. Structural efficiencies were assessed in term of ratio of operating empty weight (OEW) to maximum takeoff weight (MTOW) $[4,73]$. The use of advanced composite material has reduced the structural weight of aircrafts [76]. Therefore, our construct include the TSFC, L/D ratio, OEW, and MTOW for the measurement of ATD dimension.

\subsubsection{Aviation operations}

$\mathrm{AO}$ is another important dependent factor related to the fuel efficiency. According to Peeters et al. [62] and Hileman et al. [32] improved aviation operations have resulted in better value of fuel efficiency. The relationships between operational efficiency and efficiency are expressed by payload fuel efficiency equation $[21,32]$. Therefore, aircraft operational efficiency were measured in terms of parameters such as aircraft range [4, 51], fuel weight, reserve fuel weight, payload, aircraft speed, crew weight, takeoff filed length, and landing filed length $([2,4,5,27,29,65])$. Aircraft range is the total distance that an aircraft can fly with full fuel tank. We can improve the aircraft fuel consumption by optimizing the aircraft range. Optimized fuel weight, reserve fuel weight, and crew weight have also contributed toward the improved fuel efficiency $[2,27]$. The payload rate is another operational performance indicator that is commonly used to assess fuel burn. Air transport emission can be reduced with increased payload (reduce the number of empty seats flown) while optimizing the flight frequencies. Also, optimized aircraft speed [5], has also improved the fuel efficiency of airliners $[4,65]$. Optimum values of takeoff filed length, and landing filed length also affects positively the fuel efficiency. So, therefore we have included the aircraft range, fuel weight, reserve fuel weight, payload, aircraft speed, crew weight, takeoff filed length, and landing filed length to measure $\mathrm{AO}$ construct.

H2 (AOI) - The effective aviation operation \& infrastructure contribute positively towards the ERP.

\subsubsection{Alternate fuels \& their properties}

AFP is another important independent factor related to the fuel efficiency. A viable alternative aviation fuel can stabilize fuel price fluctuation and reduce the reliance from the crude oil. Due to the high growth rate of aviation sector, supply security of fuel, and environmental impact of fuel has caused the aviation industry to investigate the potential use of alternative fuels [8]. Presently, it appears that a blend of kerosene and synthetic fuel will be possible for use in existing and nearterm aircraft [7]. While, future mid-term aircraft may use a blend of bio-fuels and synthetic fuels in ultra-efficient airplane designs, and future long term engines and aircraft in the 50plus year horizon may be specifically designed to use alternative fuels with low to zero carbon content, such as liquid hydrogen or liquid methane [82]. Hence, based on past studies, we tried to balance several factors when selecting AFP measures. The AFP parameters including fuel availability, net calorific value, energy density, aromatic content, carbon content, thermal stability, and flash point $[7,8,33,41,73,74]$ were shown to influence fuel efficiency, and hence were incorporated in the current study.

Net calorific value and density are important parameters in determining the performance of any aviation fuel [58]. Net calorific value of a fuel portion is the amount of heat evolved when a unit weight of the fuel is completely burnt and water vapor leaves with the combustion products without being condensed. One of the most important requirements of aviation fuel is high net calorific value for maximum range or payload [8]. Energy density is the amount of energy stored in a given system or region of space per unit volume. High energy density per unit volume or mass, provides long-range flight, and decreases takeoff weight and improves fuel efficiency [40]. Also, aromatic content is another indicator affecting the FEAT. One of the biggest concerns of alternative fuels has come from their low aromatic content. In addition, the carbon content is another most essential indicator affecting the FEAT. Carbon particles that are not completely consumed are responsible for the higher specific fuel consumption of the engine [33]. Similarly, the parameters such as thermal stability and flash point [8] have shown the positive relation with the FEAT. Therefore, best alternative fuel amongst the alternative 
fuels can be selected on the basis of compatibility with aircraft operations, fuel production technology, chemical, and physical properties of fuel. Therefore, we hypothesized that:

H1: The AFP is positively related to ATD.

H2: The AFP is positively related to AO.

\subsubsection{Socioeconomic \& policy measures}

SEP is another important independent factor related to the fuel efficiency. The SEP was analyzed from several dimensions. Based on past studies, we tried to balance several factors when selecting SEP measures. The SEP parameters including social demand, fuel cost, voluntary measures, demand shift, passenger load factor, charging carbon emission, and taxing aviation fuel $[12,46,52,68,69,72,74]$ were shown to influence fuel efficiency, and hence were incorporated in the current study.

Currently, the social demand for fuel efficient and lowemission aircraft is not strong enough because the general public is not well aware of the effects of aviation emissions on the global climate [52]. Also, the fuel cost is the main driver for improvements to aircraft fuel efficiency [4, 74]. When fuel cost soar, airlines actively adopt advanced aircraft with greatly improved fuel efficiency. Another potential fuel efficiency measure is voluntary agreement [80] to meet environmental targets and funding of research to better understand the impact of aircraft higher fuel consumption. Demand shift [68] relates to another set of parameters affecting the FEAT, which account for changes in travelers' mode choice behavior (such as high speed trains, urban rail transit) or reduction of demand due to non-travel alternatives (such as videoconferencing, virtual meetings) [31] etc. In addition, the charging carbon emission is another most essential indicator affecting FEAT [9]. Finally, fuel tax [46] was also included in the study, which affects the fuel efficiency. Furthermore, high fuel prices may inspire manufacturers to focus on ATD which reduce fuel burn, rather than maximizing passenger comfort. These parameters could influence the success of SEP measures aimed at reducing aviation's fuel burn through technological intervention. Also, the study of Singh and Sharma [73] had shown that the positive correlation exist between SEP and AO. Therefore, we hypothesized that:

H3: The SEP is positively related to ATD.

H4: The SEP is positively related to AO.

\subsubsection{Aviation infrastructure}

AI also another important independent factor related with the fuel efficiency. Infrastructure improvements present a major opportunity for fuel efficiency improvement. Congestion at the airport and inappropriate air traffic management raised the fuel burn of an aircraft [4]. We have included the independent variables- origin airport, destination airport, flight profile, runway design, taxiway, apron, and weather conditions, as suggested by Senzig et al. [67]; Upham et al. [77]; Kazda and Caves [45]; IATA [37]; Salah [66]; Simaiakis et al. [71]; Singh and Sharma [74] for AI construct. There are a number of ways that airports, airlines and air traffic management providers can improve the air transportation system to minimize fuel burn. These include improving the use of the airspace, air traffic control, and operations. Further, improving the use of airspace and air traffic control includes the flexible use of airspace, route redesign, using the new tools and programmes to find most effective route, and reduced separation between the aircraft [26, 32]. Also, developed AI has contributed to the ATD and AO for fuel improvement [26, 74].

Finally, the study of Singh and Sharma [73] had analyzed the positive correlation between AI-AFP, AFP-SEP, and AISEP. Therefore, we hypothesized that:

H5: The AI is positively related to ATD.

H6: The AI is positively related to AO.

H7: The AI is positively correlated to AFP.

H8: The AFP is positively correlated to SEP.

H9: The AI is positively correlated to SEP.

\subsubsection{Respondents' type as a moderating effect on SEP and ATD}

Respondents type have different understandings of outcomes they expect to get from FEAT because of the different nature of their functioning industry; also they are exposed to different organization environment i.e. aviation or academic, which may influence them in answering the survey questionnaires. Kim [47] examined the moderating effects of job relevance and experience on mobile wireless technology acceptance; the results found that significant moderating effect of job relevance. Therefore, we insisted that individuals' understanding about the importance of FEAT to their industry type would strengthen the relationship between SEP and ATD toward the FEAT. Thus, we hypothesized:

H3a: Industry type moderates the positive effect of SEP on ATD such the effect is stronger for aviation industry respondents than for academic respondents.

\subsubsection{Experience as a moderating effect on SEP and AO}

The effect of SEP might change with prior experience. Experience has been considered as a key in relating individual differences. Ismail and Jenatabadi [39] analyzed the 
moderating effect of firm age on the relationships of airline performance, economic situation and internal operation. The results analyzed that significant moderating effect of lower age group and higher age group. It was, however, vital to examine closely at the influence of prior experience. Thus, to examine a user's beliefs concerning BI on MWT, prior experience was considered by adding.

Therefore, we observed that there was a moderating effect of user experience (lower experience group, higher experience group) on the importance of SEP and AO as determinants of FEAT. Thus, we hypothesized:

H4a: Experience moderates the positive effect of SEP on AO such that the effect is stronger for higher experienced respondents than for lower experienced respondents.

\subsubsection{Interplay between SEP, ATD, and AFP}

We argue that when SEP measures are low, then there will be positive relationship between ATD and AFP for FEAT. Low or optimum SEP measures do not put pressure on airline to raise the ticket prices, to improve the technologies, and to adopt the suitable alternative fuel for fuel efficiency improvement $[32,52]$. In contrast, high SEP measures do not maintain a focus on travel demand rather than ATD and AFP. Thus, we hypothesized:

H1b: An increase in SEP will strengthen the negative relationship between ATD and AFP.

\subsubsection{Interplay between SEP, AO, and AI}

Finally, we argue that when SEP measures are low, then there will be positive relationship between AO and AI for FEAT. Low or optimum SEP measures create the opportunities for AI improvements, and implementation of successful measures AO for better fuel efficiency $[26,50]$. In contrast, high SEP measures put pressure on airlines. Thus, we hypothesized:

H6b: An increase in SEP will strengthen the negative relationship between $\mathrm{AO}$ and $\mathrm{AI}$.

\subsection{Research model}

The conceptual research model of FEAT is shown in Fig. 1. Because ATD, AO, AFP, SEP, and AI are represented by more than one measure, and these measures are related, each of the measurements can be represented by a latent variable. The above hypotheses reveals that AFP, SEP, and AI have a positive and direct effect on ATD and AO. Therefore, hypotheses
$\mathrm{H} 1, \mathrm{H} 2, \mathrm{H} 3, \mathrm{H} 4, \mathrm{H} 5$, and $\mathrm{H} 6$ have a positive and direct effect on FEAT. Also, as shown in Fig. 1 hypotheses H3a, industry type respondents $(1=$ Academic, $2=$ Aviation $)$ is a full mediator of the impact of SEP on ATD. In addition, as depicted in Fig. 1 hypotheses $\mathrm{H} 4 \mathrm{a}$, respondent's experience (1=Low, 2=High) is a full mediator of the impact of SEP on AO. Finally, hypotheses $\mathrm{H} 1 \mathrm{~b}$ and $\mathrm{H} 6 \mathrm{~b}$ shows the interplay between AFP X SEP $\rightarrow$ ATD, and AI X SEP $\rightarrow$ AO.

The current study includes age and education level into the research model as control variables. This is important, because these variables may be significantly related to study constructs and may have confounding effects on the hypothesized relationships. Further description of the decision variables is given in the appendix A.

\section{Methodology}

\subsection{Instrument development}

A survey instrument was developed in order to test the research model. Initially, the measurement items were reviewed by five aviation experts who were asked to comment on the appropriateness of the research constructs. Based on the assessment from the experts, redundant and ambiguous items were either changed or eliminated. New items were finally accepted and included in the questionnaire. Hence, the content validity of the survey instrument was considered as appropriate. The questionnaires along with a covering letter mentioning objectives of the study were sent to various persons of government and private organizations dealing with the aviation. The specific sampling strategy was stratified random sampling. The main reasons for using a specific sampling strategy were to increase the precision in FEAT research and to reduce the sample variation and error.

This empirical study was carried out in the time period from January, 2014 to December, 2015. It took approximately 1 year of span for data gathering. The study was conducted in two parts the first part was provided with demographic information's such as; gender, working experience in organization, category of organization, title of the post and in the second part responses to the questions were based on a five-point Likert scale ranging from " $1=$ strongly disagrees" to " $5=$ strongly agree". The questionnaires were distributed to the 1200 participants and finally 421 the questionnaires were completed. The response rate was $35 \%$ and out of 421 respondents 46 questionnaires were excluded due to missing data. So numbers of valid samples were 375. The majority of the respondents were male. Specifically, $288(77 \%)$ respondents were male and 87 (23\%) were female. One hundred twenty six (34\%) respondents were aged between 24 and 34 years, 97 (26\%) were aged between 35 and 44 years, and 65 (17\%) were 


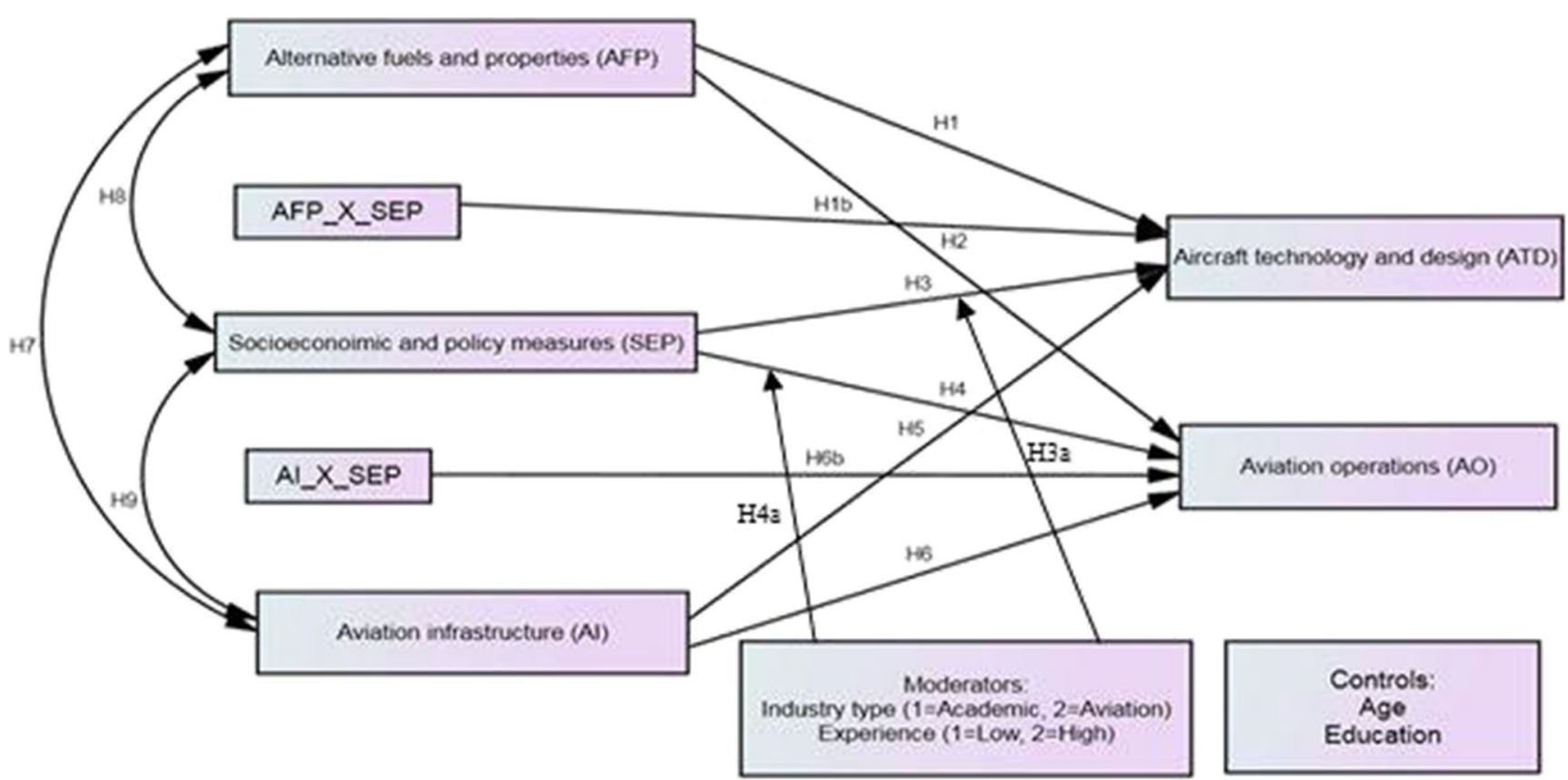

Fig. 1 Research model of FEAT

aged between 45 and 54 years. The rest were older than 55 . With respect to educational level, One hundred two (27\%) respondents had the graduation degree, while 129 (34\%) had the masters degree. The rest had $\mathrm{PhD}$ degrees. One hundred and sixty-six (44\%) respondents were from academic organization and 209 (56\%) respondents were from aviation organization. One hundred and fifty-nine (42\%) respondents had the experience between 3 and 15 years, and $131(26 \%)$ had the experience between 16 and 30 years. The rest had the experience more than 31 years. In addition, the participants are divided into two major experience group i.e. low experience (between 3 and 15 years) and high experience (16 years and above). Furthermore, sample have included the occupation detail of respondents i.e. 39 directors $(10 \%), 63$ managers $(17 \%), 96$ research scientists $(26 \%), 11$ aircraft pilots (3\%), 37 (10\%) professors, 48 (13\%) assoc. professors, $55(15 \%)$, asst. professors, 14 (4\%) lecturers, and 12 (3\%) senior lecturers. Table 1 shows the demographic characteristics of the sample.

\subsection{The measuring instruments}

The proposed model incorporates five constructs related to ATD, AOI, AFP, SEP, and AI. In total, 33 questions were used to measure the five constructs. Since the five constructs in the proposed model of FEAT are unobserved variables, observed variables are designed as survey instrument to measure the five constructs. The questionnaire composed of two parts. The first part was provided with demographic characteristics of the sample as shown in
Table 1 and in the second part responses to the questions were based on a five-point Likert scale ranging from " $1=$ strongly disagrees" to " $5=$ strongly agree". The second part covers with the measurement of ATD with 4 items, AO with 8 items, SEP with 7 items, AFP with 7 items, and finally, the fifth construct with 7 items.

\subsection{Techniques of data analysis}

Structural equation modelling (SEM) is a multivariate technique that allows the simultaneous estimation of multiple equations comprising factor analysis, multiple regression analysis, and path model analysis [28]. SEM is a handy statistical tool for evaluating the whole set of relationships among the latent constructs that are indicated by multiple measures defining a research model and for differentiating between the indirect and direct relationships between the latent constructs $[24,73,79]$.

SEM includes two types of factor: exploratory and confirmatory factor analysis. Exploratory factor analysis (EFA) is employed to obtain the structure of a set of measured data [28]. EFA assesses the construct validity during the initial development of an instrument [73]. While in confirmatory factor analysis (CFA) is used to validate the hypotheses unobserved variables and latent variables [28]. In conducting SEM analysis, EFA was used to extract the principal factors, and CFA was then employed to validate the factor structure of the FEAT elements. SEM for FEAT perception was proposed using the factor structure from the CFA results. The AMOS 20.0 software package was employed to examine CFA and SEM. 
Table 1 Demographic characteristics of the sample

\begin{tabular}{|c|c|c|}
\hline Demographic categories & Frequency & Percentage $(\%)$ \\
\hline \multicolumn{3}{|l|}{ Gender } \\
\hline Male & 288 & 77 \\
\hline Female & 87 & 23 \\
\hline \multicolumn{3}{|l|}{ Age (years) } \\
\hline $24-34$ & 126 & 34 \\
\hline $35-44$ & 97 & 26 \\
\hline $45-54$ & 65 & 17 \\
\hline 55 and above & 87 & 23 \\
\hline \multicolumn{3}{|l|}{ Education level } \\
\hline Graduation & 102 & 27 \\
\hline Masters & 129 & 34 \\
\hline Ph.D or Doctorate & 144 & 38 \\
\hline \multicolumn{3}{|l|}{ Industry type } \\
\hline Academics & 166 & 44 \\
\hline Aviation & 209 & 56 \\
\hline \multicolumn{3}{|l|}{ Experience level } \\
\hline $3-15$ & 159 & 42 \\
\hline $16-30$ & 131 & 35 \\
\hline 31 and above & 85 & 23 \\
\hline \multicolumn{3}{|l|}{ Occupation } \\
\hline Directors & 39 & 10 \\
\hline Managers & 63 & 17 \\
\hline Research scientists & 96 & 26 \\
\hline Aircrafts pilots & 11 & 3 \\
\hline Professor & 37 & 10 \\
\hline Associate professors & 48 & 13 \\
\hline Assistant professors & 55 & 15 \\
\hline Lecturer & 14 & 4 \\
\hline Senior lecturer & 12 & 3 \\
\hline
\end{tabular}

\section{Data analysis}

\subsection{Data screening}

Data screening is the procedure of checking the data for errors and fixing or removing these errors. We have conducted the data screening in order to ensure the data is useable, reliable, and valid for testing causal theory.

Missing data: ATD2 and AFP3 had one missing value, which we imputed with the median. Missing values, occur when no data value is stored for the variable in an observation. The missing values can arise due to carelessness in observation, errors made during data entry, data loss due to misplacement etc. We have used median imputation because ATD2 and AFP3 are an ordinal variables (were measured using a Likert scale). In addition, controlling for outliers and maintaining the normal distribution help in controlling the diversity of the data.

Normality: The normality testing used in SEM is based on the value of skewness and kurtosis [10, 28]. If the absolute kurtosis value of skewness and kurtosis is between +2 and -2 , the endogenous variables normality is acceptable [10,59]. As Table 2 displays, skewness ranges between -.047 and -1.000 and kurtosis values range between 1.967 and -.182; the absolute value of kurtosis and skewness are less than \pm 2 . Hence, the normality of the endogenous variables is acceptable. Additionally, the standard deviation of all the items was above 0.5 on five point scale. Therefore, their responses exhibit enough variance for better analysis.

Table 2 Normality test of FEA decision variables

\begin{tabular}{|c|c|c|c|}
\hline Decision variables & Skewness & Kurtosis & Std. Deviation \\
\hline AFP1 & .316 & -.364 & .831 \\
\hline AFP2 & .122 & -.782 & .893 \\
\hline AFP3 & .318 & -.445 & .885 \\
\hline AFP4 & -.265 & -.725 & .927 \\
\hline AFP5 & -.058 & -.879 & .946 \\
\hline AFP6 & -.093 & -.923 & .955 \\
\hline AFP7 & .069 & -.637 & .897 \\
\hline SEP1 & -.699 & 1.019 & .704 \\
\hline SEP2 & -.724 & 1.374 & .703 \\
\hline SEP3 & -.590 & .978 & .705 \\
\hline SEP4 & -.597 & 1.232 & .682 \\
\hline SEP5 & -.592 & .963 & .701 \\
\hline SEP6 & -.605 & 1.097 & .662 \\
\hline SEP7 & -.374 & -.006 & .687 \\
\hline AI1 & -.406 & -.215 & .927 \\
\hline AI2 & -.456 & -.182 & .930 \\
\hline $\mathrm{AI} 3$ & -.630 & .267 & .909 \\
\hline AI4 & -1.000 & 1.331 & .829 \\
\hline AI5 & -.283 & -.441 & .956 \\
\hline AI6 & -.665 & .336 & .859 \\
\hline $\mathrm{AI} 7$ & -.773 & .698 & .861 \\
\hline ATD1 & -.893 & 1.901 & .670 \\
\hline ATD2 & -.660 & 1.243 & .650 \\
\hline ATD3 & -.325 & 1.946 & .549 \\
\hline ATD4 & -.567 & 1.328 & .631 \\
\hline AO1 & -.739 & 1.048 & .761 \\
\hline $\mathrm{AO} 2$ & -.897 & 1.967 & .723 \\
\hline $\mathrm{AO} 3$ & -.614 & 1.028 & .733 \\
\hline $\mathrm{AO} 4$ & -.729 & 1.021 & .762 \\
\hline AO5 & -.690 & 1.124 & .713 \\
\hline AO6 & -.748 & .711 & .811 \\
\hline $\mathrm{AO} 7$ & -.511 & .728 & .740 \\
\hline $\mathrm{AO} 8$ & -.047 & -.465 & .901 \\
\hline
\end{tabular}




\subsection{Exploratory factor analysis}

We conducted an EFA using maximum likelihood with promax rotation to see if the observed variables loaded together as expected, were adequately correlated, and met criteria of reliability and validity. Maximum likelihood estimation was chosen in order to determine unique variance among items and the correlation between factors, and also to remain consistent with our subsequent CFA. Maximum Likelihood also provides a goodness of fit test for the factor solution. Promax was chosen because the dataset is quite large $(n=375)$ and promax can account for the correlated factors. We have addressed each of these below for the final five-factor model depicted in the pattern matrix below.

\subsubsection{Adequacy}

Before conducting the exploratory factor analysis (EFA), the Bartlett's test of sphericity and Kaiser-Meyer-Olkin (KMO) measure of sampling adequacy were used to assess the suitability of the questionnaire. The results reveal that $\mathrm{KMO}=0.937$ and Bartlet's test is significant at $\alpha=0.000$ with a Chi-square of 9779.544 , indicating the suitability of conducting exploratory factor analysis, according to Kaiser [44]. After EFA, the individual items AFP1, AO6, and AO8 had the low communalities less than 0.400 . Therefore, they were removed from the study.

In this study, factor loadings of 0.50 and higher will be considered practically significant [28, 30]; Lai and Chen [49]. Also, the AO1, and AO7 were not sufficiently loaded to their factor, so were also neglected. Finally, after removing these items, the communality for each item were sufficiently high (all above 0.500), thus indicating the chosen variables were adequately correlated for a factor analysis. Additionally, the reproduced matrix had only $4 \%$ non-redundant residuals greater than 0.05 , further confirming the adequacy of the variables and 5-factor model.

\subsubsection{Reliability}

Reliability for each of the factor was calculated using Cronbach's $\alpha$ coefficient. The Cronbach's $\alpha$ coefficient ranged from 0.849 to 0.938 , as shown in Table 3 . All the factors'

Table 3 Relibility of FEAT factors

\begin{tabular}{ll}
\hline Factor Label & Cronbach's alpha \\
\hline ATD & 0.892 \\
AO & 0.849 \\
AFP & 0.915 \\
SEP & 0.912 \\
AI & 0.938 \\
\hline
\end{tabular}

reliability values were above the cut-off criterion of 0.7 recommended by Nunnally [60]; Hair et al. [28]; Cortina [19].

\subsubsection{Validity}

The Table 4 below illustrates a very clean factor structure in which convergent and discriminant validity are evident by the high loadings within factors, and no cross-loadings between factors. The factors demonstrate sufficient convergent validity, as their loadings were all above the 0.600 for a samples size of 375. Table 4 shows the factor loadings for each of the factor.

Also, the factors demonstrate sufficient discriminant validity, as the correlation matrix Table 5 shows no correlations above 0.700 . Finally, this five-factor model had a

Table 4 Pattern matrix

\begin{tabular}{|c|c|c|c|c|c|}
\hline \multirow[t]{2}{*}{ Parameters } & \multicolumn{5}{|c|}{ Factor } \\
\hline & 1 & 2 & 3 & 4 & 5 \\
\hline AFP2 & & & .802 & & \\
\hline AFP3 & & & .707 & & \\
\hline AFP4 & & & .677 & & \\
\hline AFP5 & & & .924 & & \\
\hline AFP6 & & & .929 & & \\
\hline AFP7 & & & .696 & & \\
\hline SEP1 & .808 & & & & \\
\hline SEP2 & .807 & & & & \\
\hline SEP3 & .946 & & & & \\
\hline SEP4 & .972 & & & & \\
\hline SEP5 & .852 & & & & \\
\hline SEP6 & .692 & & & & \\
\hline SEP7 & .668 & & & & \\
\hline AI1 & & .662 & & & \\
\hline AI2 & & .866 & & & \\
\hline $\mathrm{AI} 3$ & & .823 & & & \\
\hline AI4 & & .868 & & & \\
\hline AI5 & & .842 & & & \\
\hline AI6 & & .788 & & & \\
\hline AI7 & & .886 & & & \\
\hline ATD1 & & & & & .715 \\
\hline ATD2 & & & & & .705 \\
\hline ATD3 & & & & & .674 \\
\hline ATD4 & & & & & .778 \\
\hline $\mathrm{AO} 2$ & & & & .825 & \\
\hline $\mathrm{AO} 3$ & & & & .902 & \\
\hline $\mathrm{AO} 4$ & & & & .754 & \\
\hline AO5 & & & & .716 & \\
\hline
\end{tabular}


Table 5 Factor correlation matrix

\begin{tabular}{llllll}
\hline Factor & 1 & 2 & 3 & 4 & 5 \\
\hline 1 & 1.000 & .487 & .358 & .526 & .550 \\
2 & .487 & 1.000 & .528 & .369 & .509 \\
3 & .358 & .528 & 1.000 & .265 & .408 \\
4 & .526 & .369 & .265 & 1.000 & .613 \\
5 & .550 & .509 & .408 & .613 & 1.000 \\
\hline
\end{tabular}

Extraction Method: Maximum Likelihood

Rotation Method: Promax with Kaiser Normalization

total variance explained of $67.105 \%$, with all five extracted factors having eigenvalues above 1.0. The five factors in terms of FEAT perceptions derived from EFA were similar to those in previous studies [73, 74]. This confirmed that fuel efficiency perception can be summarized as ATD, $\mathrm{AO}, \mathrm{AFP}, \mathrm{SEP}$, and AI.

\subsection{Confirmatory factor analysis}

\subsubsection{Model fit}

All the constructs have items with significant loadings $\geq 0.70$. Modification indices were consulted to determine if there was opportunity to improve the model. Accordingly, we covaried the error terms between e2-e5, e3-4, e6-e7, e12-e13, e12-e14, e13-e14, e18-19, and e2324. Figure 2 shows the measurement model of FEA. The Table 6 below indicates that the goodness of fit for our measurement model is sufficient.

\subsubsection{Validity and reliability}

- To test for convergent validity (CV) we estimated the average variance extracted (AVE). Table 7 shows that the AVE are ranging from 0.588 to 0.687 , so all values are above the recommended 0.50 levels [23], indicating that the convergent validity of the measurement model is confirmed.

- To test for discriminant validity we compared the square root of the AVE (on the diagonal in the Table 7 below) to all inter-factor correlations. Table 7 shows that the mean shared variance $(M S V s)<$ AVEs. This was significantly lower than their individual AVEs. The results have demonstrated evidence of discriminate validity for the study constructs (Table 7).

- We also computed the composite reliability (CR) for each construct. In all cases the $\mathrm{CR}$ was above the minimum threshold of 0.70 [28], indicating we have reliability in our constructs.

\subsubsection{Common method bias}

Because the data for both independent variables and dependent variables was collected using a single instrument (a survey), we conducted a common method bias test to determine if a method bias was affecting the results of our measurement model. Figure 3 shows the Common Latent Factor (CLF) based model. The test we used was the "unmeasured latent factor" method recommended by Podsakoff et al. [64] and Siemsen et al. [70] for studies that do not explicitly measure a common factor (as in this work). Comparing the standardized regression weights before and after adding the CLF shows that none of the regression weights are dramatically affected by the CLF-i.e., the deltas are less than 0.200 and the CR and AVE for each construct still meet minimum thresholds. Nevertheless, to err on the conservative side, we have opted to retain the CLF for our structural model (by imputing composites in AMOS while the CLF is present), and thus we have CMB-adjusted values.

\subsubsection{Invariance tests}

Since we are planning on moderating the structural model with two categorical variables, we conducted configurable and metric invariance tests.

- Industry type: The model fit of the unconstrained measurement models (with groups loaded separately) had adequate fit $\left(\chi^{2} / \mathrm{DF}=1.587 ; \mathrm{CFI}=0.964\right)$, indicating that the model is configurally invariant. After constraining the models to be equal, we found the chi-square difference test to be significant $(p=0.000)$. Thus, our measurement model meets criteria for metric invariance across industry type as well.

- Experience: The model fit for experience was equally $\operatorname{good}\left(\chi^{2} / \mathrm{DF}=1.605 ; \mathrm{CFI}=0.964\right)$. The chi-square difference test was again significant $(p=0.000)$.

\subsection{SEM analysis}

\subsubsection{Multivariate assumptions}

Linearity: We tested linearity by performing curve estimation regression for all direct effects in our model. The results show that the relationships between variables are sufficiently linear (i.e., all p-values were less than 0.05 ).

Multicollinearity: We tested the Variable Inflation Factor (VIF) for all of the exogenous variables simultaneously. The VIFs were all less than 2.0, indicating that the exogenous variables are all distinct. 


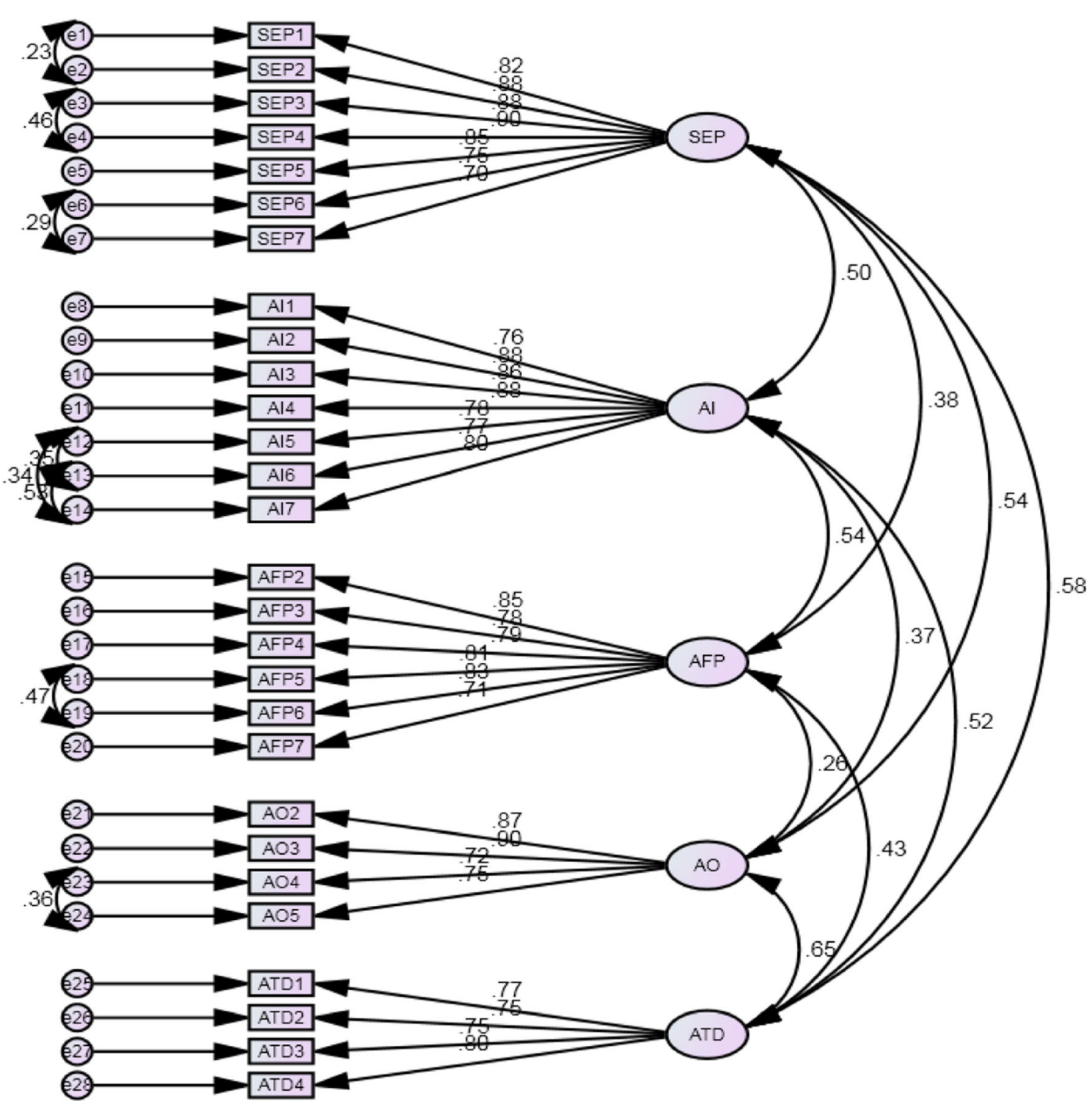

Fig. 2 Measurement model of FEAT

Table 6 Goodness of fit statistics in CFA

\begin{tabular}{llcll}
\hline Indices & Abbreviation & Observed values & Recommended criteria & References \\
\hline Chi square & $\chi^{2}$ & 578.677 & pval $>0.05$ & Hair et al. [28]; \\
Normed chi square & $\chi^{2} / \mathrm{DF}$ & 1.743 & $1<\chi^{2} / \mathrm{df}<3$ & Byrne [10]; \\
Goodness-of-fit index & GFI & 0.904 & $>0.90$ & Hu and Bentler [35]; \\
Adjusted GFI & AGFI & 0.883 & $>0.80$ & Jöreskog and Sörbom [43] \\
Normed fit index & NFI & 0.933 & $>0.90$ & $>0.95$ \\
Comparative fit index & CFI & 0.970 & $<0.05$ good fit & \\
Root mean square error of approximation & RMESA & 0.045 & $<0.08$ acceptable fit & \\
Tucker-Lewis index & & & $0<$ TLI $<1$ & \\
\hline
\end{tabular}


Table 7 Reliability and validity in CFA

\begin{tabular}{llllllllll}
\hline & CR & AVE & MSV & ASV & AO & SEP & AI & AFP & ATD \\
\hline AO & 0.884 & 0.658 & 0.423 & 0.230 & 0.811 & & & & \\
SEP & 0.938 & 0.687 & 0.339 & 0.256 & 0.541 & 0.829 & & & \\
AI & 0.934 & 0.669 & 0.296 & 0.240 & 0.369 & 0.502 & 0.818 & & \\
AFP & 0.912 & 0.634 & 0.296 & 0.174 & 0.262 & 0.377 & 0.544 & 0.796 & \\
ATD & 0.851 & 0.588 & 0.423 & 0.306 & 0.650 & 0.582 & 0.524 & 0.434 & 0.767
\end{tabular}

Note; For Composite reliability (CR>.70); Convergent validity $(\mathrm{CR}>\mathrm{AVE}>.50)$; Discriminate validity $(\mathrm{MSV}<\mathrm{AVE}) ; \mathrm{MSV}$ Maximum shared variance, $A S V$ Average shared variance [28]

\subsubsection{Model fit of structural model}

Figure 4 displays the outcomes of the initial structured model with standardized parameters while controlling for age, and education for DVs. The fitted structural model demonstrates adequate fit. In order to achieve good fit, we additionally covaried the error terms of the DVs and controls, as we wanted to account for their correlation without adding theoretical complexity to our model. While there may exist causal relationships between these variables, this is not the focus of this model. Table 8 shows the Goodness of fit statistics of structural model. Additionally, the controls did not have a significant impact on either dependent variable, except the respondents age had a slight negative effect on ATD and AO (standardized beta for ATD and $\mathrm{AO}=-0.018^{*},-0.003 *$ ).

\subsubsection{Hypotheses testing of the research model}

All hypotheses were tested while controlling for age, and education. Controlling for variables that may influence the relationship between ATD, AO, AFP, SEP, and AI helps to minimize unrelated effects. Furthermore, it helps to improve the robustness and validity of the results.

The relationship between two DVs, i.e., ATD, AO and three IVs, i.e., AFP, SEP, AI is determined by the proposed model. The proposed model hypotheses that the ATD, AO, and AFP, SEP, and AI are directly and indirectly interrelated. The standardized path loadings and their statistical significance are shown in Table 8. It was found that nine paths out of fourteen specific hypotheses were statistically significant except for $\mathrm{H} 2, \mathrm{H} 5, \mathrm{H} 9, \mathrm{H} 1 \mathrm{~b}$, and $\mathrm{H} 6 \mathrm{~b}$.

The path coefficients in the SEM are shown in Fig. 5 and the results of the hypothesis testing are summarized in Table 9. Table 9 show that hypothesis H1 is supported, because AFP has a positive impact on ATD $(\beta=0.101, p<0.01)$. This implies that selection of suitable AFP depends upon the development of ATD, which contributes to the improvement of air transport fuel efficiency. Hence, this confirms that $\mathrm{H} 1$ is supported. Also, the path coefficient between AFP and AO is

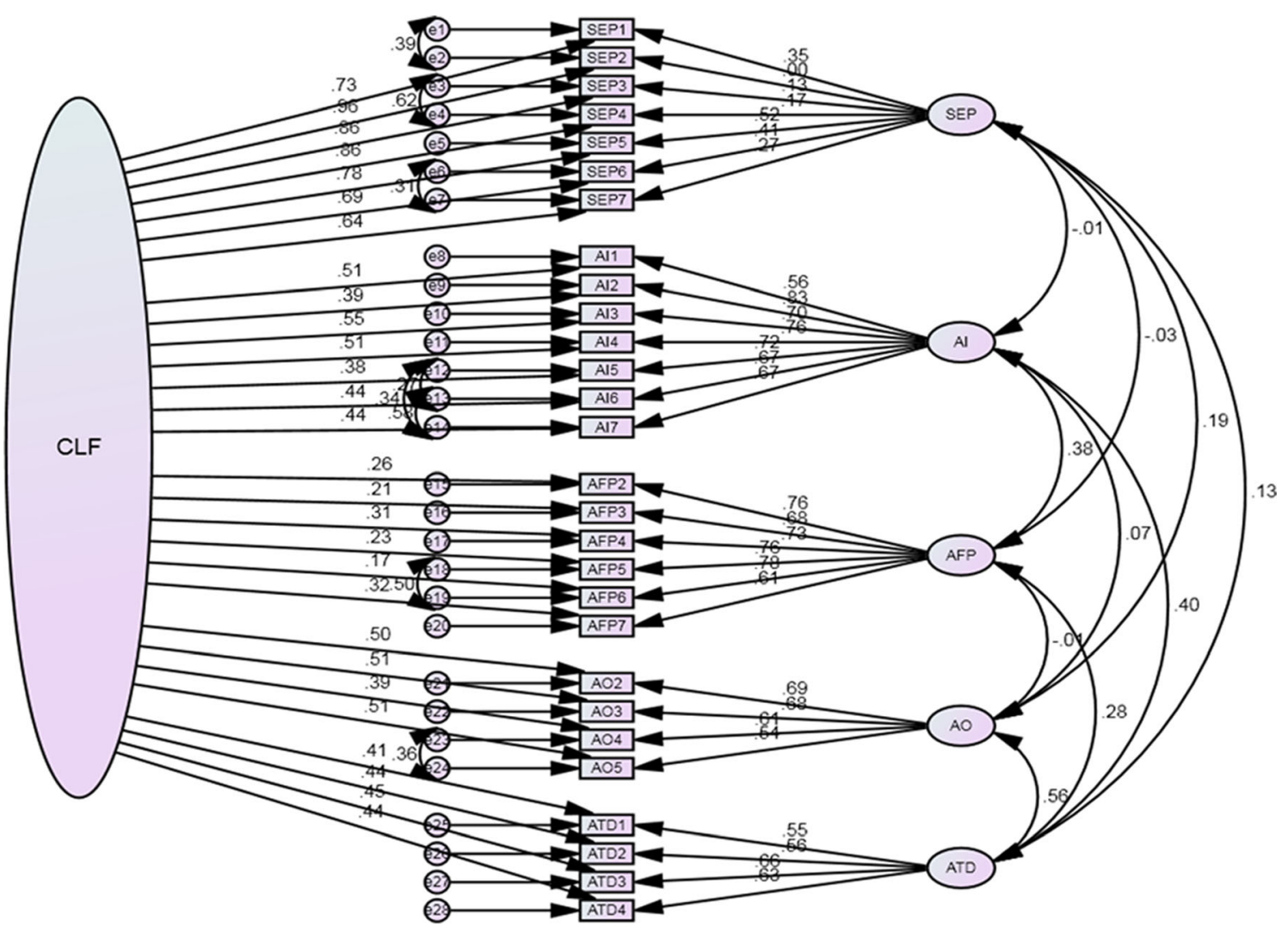

Fig. 3 The Common Latent Factor (CLF) based model of FEA 
Fig. 4 Initial structural model of FEAT

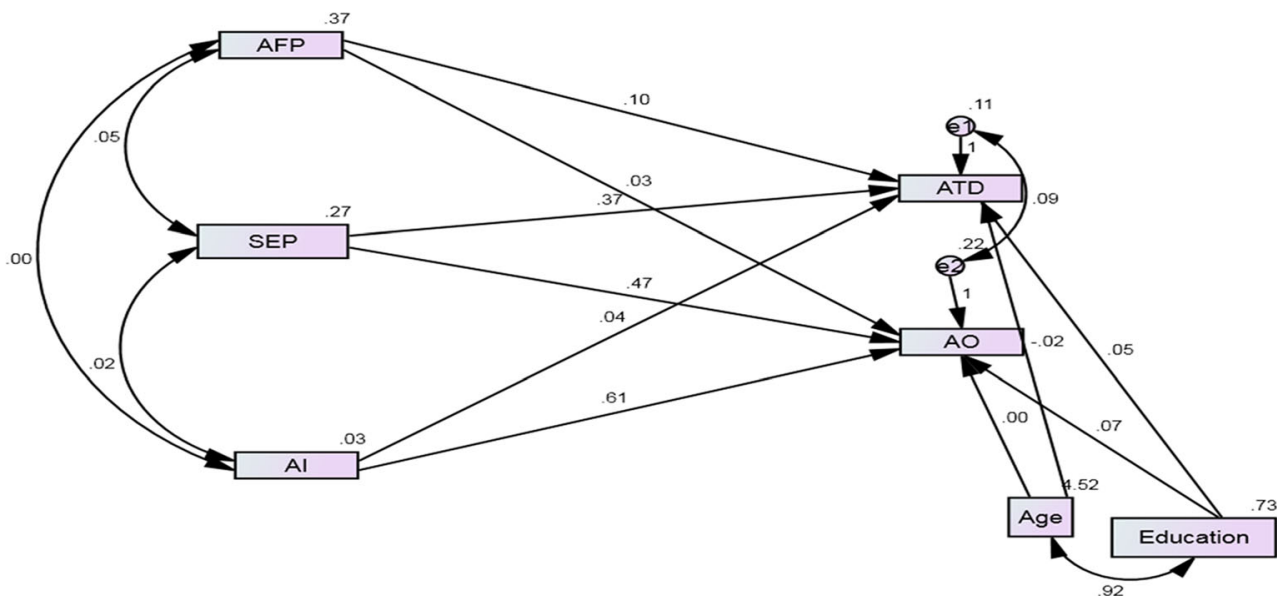

$0.035(p>0.05)$, which is a positive but not significant relation, indicating that AFP has no significant positive impact on AO. This confirms that $\mathrm{H} 2$ is not supported. The path coefficient between SEP and ATD is $0.368(p<0.01)$, which is a significant positive correlation, indicating that when air transport adopt and implement the SEP measures for ATD, their adoption and implementation increases fuel efficiency of airlines, which supports hypothesis H3.

The path coefficient between SEP and AO is 0.0467 $(p<0.01)$, which is a significant positive correlation, indicating that when air transport regulate and implement the SEP measures for optimal $\mathrm{AO}$, their regulation and implementation increases fuel efficiency of airlines, which supports hypothesis H4. The path coefficient between AI and ATD is 0.042 $(p>0.05)$, which is a positive but not significant correlation, indicating that AI has no significant positive impact on ATD. This confirms that $\mathrm{H} 5$ is not supported. The path coefficient between $\mathrm{AI}$ and $\mathrm{AO}$ is $0.609(p<0.01)$, which is a significant positive correlation, indicating that proper planned AI increases the productivity of $\mathrm{AO}$, which contributes to the improved fuel efficiency. Hence, this confirms that H6 is supported.

Also, the correlation between SEP and AFP, and SEP and AI were found to be positive $(\beta=0.053 ; 0.025)$ and significant $(p<0.01)$, and this confirms the results of previous study [73].
This indicates that the suitable amounts of SEP measures are necessary for AFP adoption and for the development of AI, which contribute to the improved fuel efficiency. Therefore, the hypothesis $\mathrm{H} 7$ and $\mathrm{H} 8$ are supported. Finally, AFP had no significant $(\beta=0.003, p>0.1)$ effects on the AI. This is somewhat at odds with previous study [73] showing that AFP had a correlation with the AI. This difference occurs because the AFP in this study was dominantly produced from near term synthetic fuels. So, there is no need to change the existing AI. This confirms that hypotheses H9 is not supported.

Multi-group moderation Multi-group moderation tests were conducted using the full model, but prior to adding the interaction variables. To test the categorical moderation hypotheses, we produced the critical ratios for the differences in regression weights between groups of industry type (academic, aviation) and experience (low, high). From these critical ratios we calculated $p$-values to determine the significance of the difference. The results are summarized in the hypotheses summary Table 9 below. The results in Table 8 indicated that SEP significantly and positively affected ATD for the both academic $(\beta=0.268, p<0.01)$ and aviation $(\beta=0.515, p<0.01)$ group respondents. This has also showed that the effect of SEP on ATD were stronger for aviation group than the academic group. Therefore, the hypothesis H3a is supported.

Table 8 Goodness of fit statistics of structural model

\begin{tabular}{lllll}
\hline Indices & Abbreviation & Observed values & Recommended criteria & References \\
\hline Normed chi square & $\chi^{2} / \mathrm{DF}$ & 1.624 & $1<\chi^{2} / \mathrm{df}<3$ & Hair et al. [28]; \\
Goodness-of-fit index & GFI & 0.993 & $>0.90$ & Byrne (2013); \\
Adjusted GFI & AGFI & 0.966 & $>0.80$ & Hu and Bentler [35]; \\
Normed fit index & NFI & 0.983 & $>0.90$ & Jöreskog and Sörbom [43] \\
Comparative fit index & CFI & 0.993 & $>0.95$ & $<0.05$ good fit \\
Root mean square error of approximation & RMESA & 0.041 & $<0.08$ acceptable fit & \\
& & & $0<$ TLI $<1$ & \\
Tucker-Lewis index & TLI & 0.976 & & \\
\hline
\end{tabular}


Fig. 5 Structural model test results

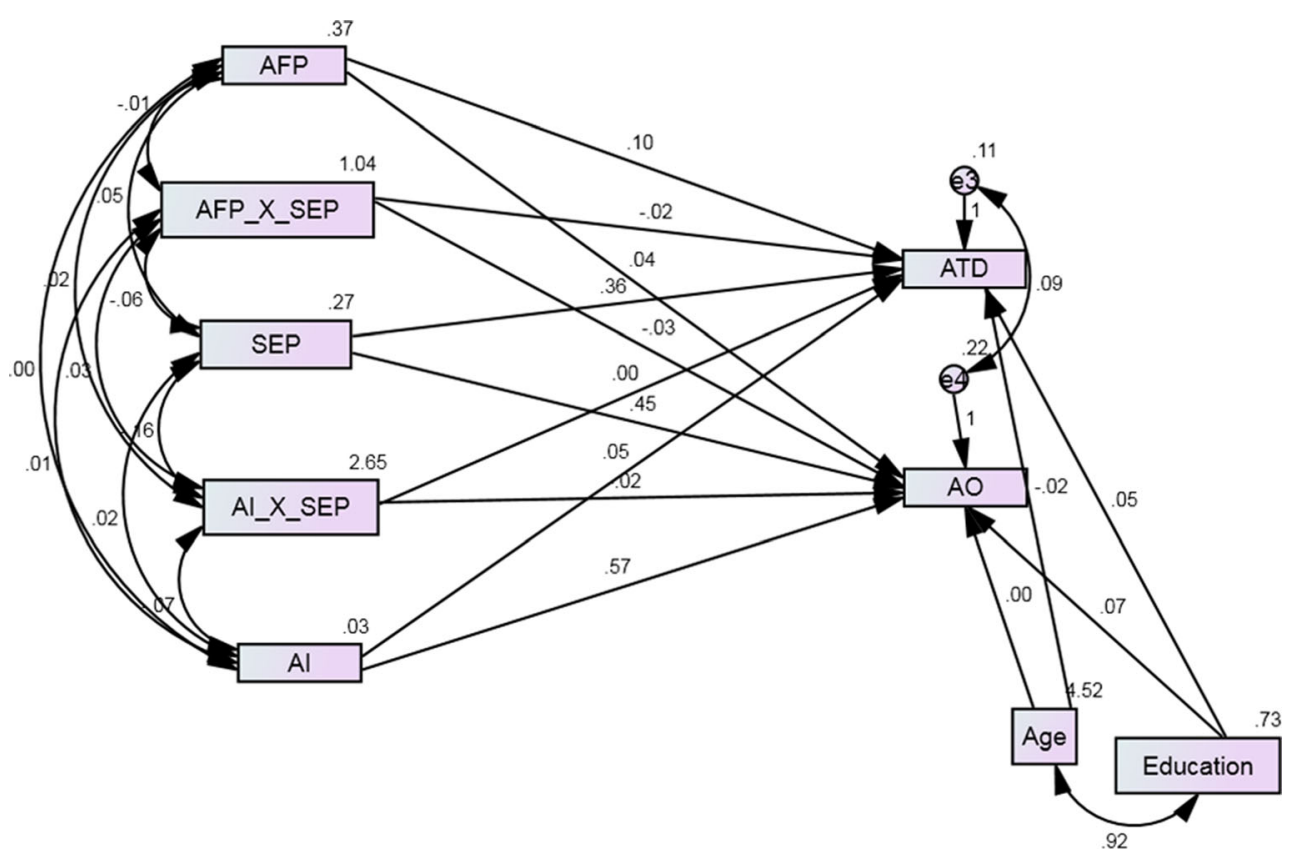

Furthermore, the results showed that SEP significantly and positively affected $\mathrm{AO}$ for both low $(\beta=0.380, p<0.01)$ and high $(\beta=0.618, p<0.01)$ experienced respondents. This has also showed that the effect of SEP on AO were stronger for highly experienced group than the low experienced group. Therefore, the hypothesis H4a is supported.
Table 9 Hypotheses summary table

\begin{tabular}{lll}
\hline Hypotheses & Evidence & Supported? \\
\hline H1: AFP $\rightarrow$ ATD & $0.101^{* * *}$ & Yes \\
H2: AFP $\rightarrow$ AO & $0.035(\mathrm{~ns})$ & Not \\
H3: $\mathrm{SEP} \rightarrow$ ATD & $0.368^{* * *}$ & Yes \\
H4: SEP $\rightarrow$ AO & $0.0467^{* * *}$ & Yes \\
H5: AI $\rightarrow$ ATD & $0.042(\mathrm{~ns})$ & Not \\
H6: AI $\rightarrow$ AO & $0.609^{* * *}$ & Yes \\
H7: SEP $\rightarrow$ AFP & $0.053^{* * *}$ & Yes \\
H8: SEP $\rightarrow$ AI & $0.025^{* * *}$ & Yes \\
H9: AFP $\rightarrow$ AI & 0.003 (ns) & Not \\
Multi-group moderation & & \\
H3a: Industry type moderates the positive effect & Academic:0.268*** & Yes: \\
of SEP on ATD that such the effect is stronger & Aviation:0.515*** & Stronger for \\
for aviation industry respondents. & $\Delta Z$ score:3.57*** & aviation respondents \\
H4a: Experience moderates the positive effect of & Experience low: $0.380^{* * *}$ & Yes: \\
SEP on AO such that the effect is stronger for & Experience high:0.618*** & Stronger for more \\
higher experience. & $\Delta Z$ Zscore:2.437*** & experienced \\
& & respondents \\
Interaction & & \\
H1b: An increase in SEP will strengthen the & Interaction effect: & Not \\
negative relationship between ATD and AFP. & -0.015 & Not \\
H6b: An increase in SEP will strengthen the negative & Interaction effect: & \\
relationship between AO and AI. & -0.022 & \\
\hline
\end{tabular}

$n s$ Not significant

$* * * p$-value $<0.01 ; * * p$-value $<0.05$ 
Fig. 6 Interaction between the AFP and SEP

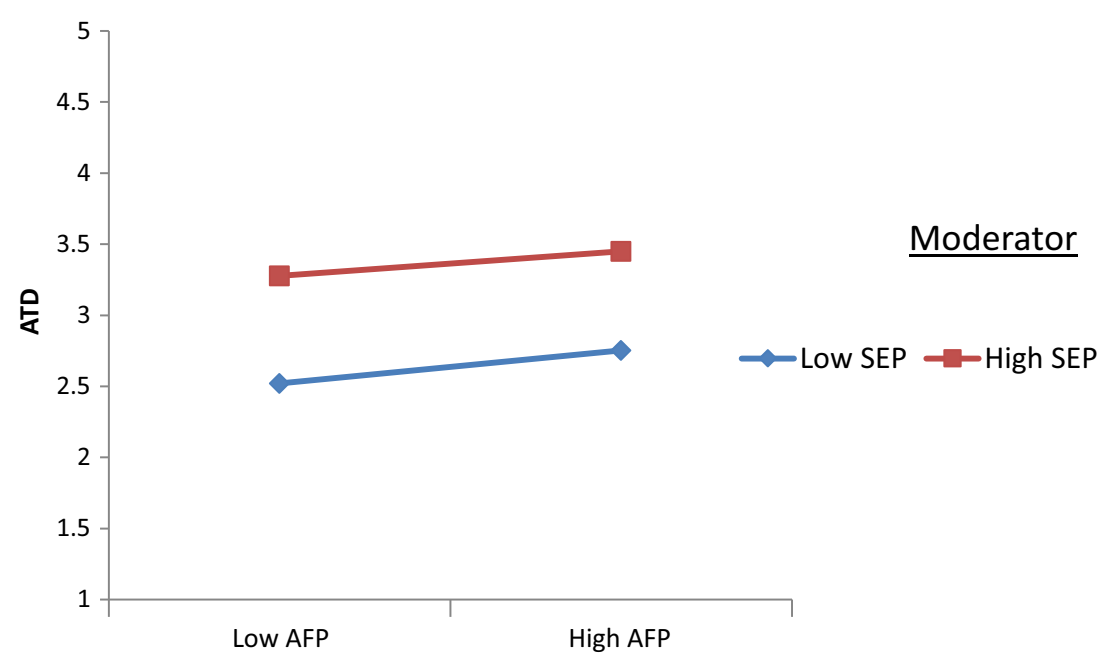

Two way interactions Interaction effects were tested using the full dataset, rather than the moderated dataset. To test the interaction hypotheses we first standardized the IVs and then created product variables. In this case, none of the interactions were significant. We plotted these interactions as shown in Figs. 6 and 7. When effect of SEP is low, then there is positive relationship between ATD and AFP as shown in Fig. 6. But, when the effect of SEP is high, then there is negative relationship between ATD and AFP. So, SEP dampens the positive relationship between ATD and AFP. Thus, the hypothesis H1b is not supported. Furthermore, when effect of SEP is low, then there is positive relationship between $\mathrm{AO}$ and $\mathrm{AI}$ as shown in Fig. 7. But, when the effect of SEP is high, then there is negative relationship between AO and AI. So, SEP dampens the positive relationship between AO and AI. Thus, the hypothesis H6b is not supported. Also, the results of the interaction tests are summarized in the Hypothesis Summary table below. Additionally, we observed that model fit was very $\operatorname{good}\left(\chi^{2} / \mathrm{DF}=1.078 ; \mathrm{CFI}=0.999 ; \mathrm{GFI}=994\right.$; $\mathrm{RMSEA}=0.014$ ) for the final moderated model.

\section{Conclusions and implications}

The study contributes to the extant literature as the instrument employed was effective in evaluating fuel efficiency in air transport and can therefore be confidently used again in FEAT related studies. This study attempts to identify the key FEAT-related factors. The results show that the key fuel efficiency improvement related factors in the air transport can be represented by five constructs (measured by 28 items), and this confirms the results of previous studies [73, 74], although, some of measured items were different. The results of this study supported the new inclusions and casual relations in the FEAT model. The effect of new inclusions and casual relations has not been examined in previous studies.

The SEM analysis showed that AFP had a significant and positive $(\beta=0.101, p<0.01)$ effect on ATD. This indicates that when we adopt new alternative fuel, air transport need to strengthen ATD for fuel efficiency improvement. The contributions of AFP and AO on fuel efficiency improvements were positive but not significant $(\beta=0.035, p>0.05)$. This means
Fig. 7 Interaction between the AI and SEP

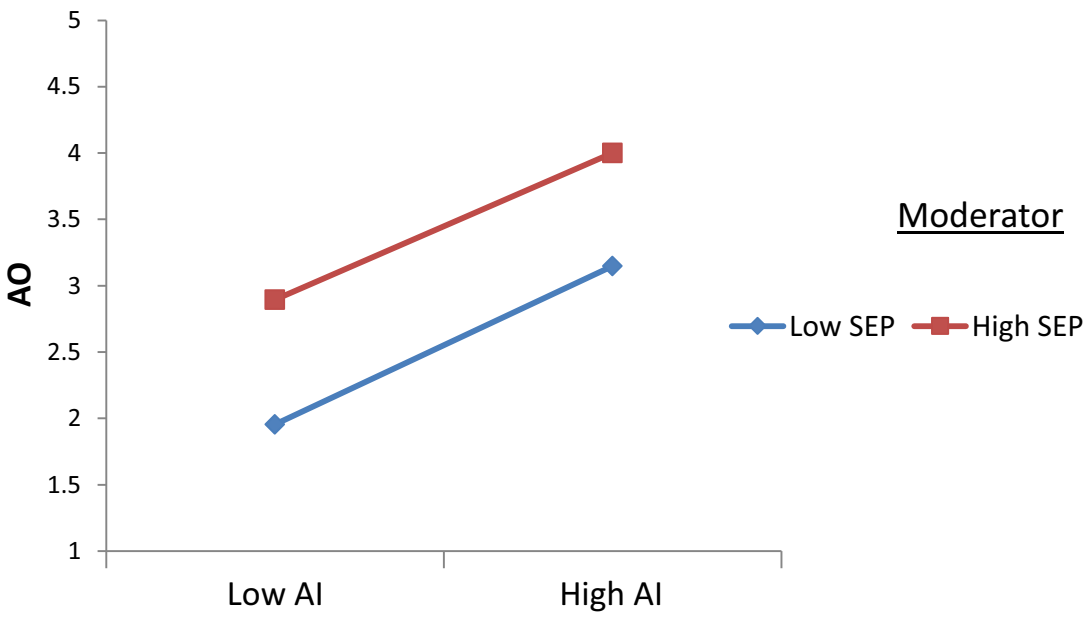


that there is no need to change the aviation operations on the adoption of new alternative fuel. The selection of new aviation alternative will on near term synthetic fuels. SEP had a significant positive effect $(\beta=0.368, p<0.01)$ on ATD. This means that SEP strategies are very important in determining the technological potentials for fuel efficiency improvement. Also, SEP had a significant positive effect $(\beta=0.0467, p<0.01)$ on AO. This implies that regulation and implementation of suitable SEP measures are necessary for optimal AO. AI had a positive but not significant $(\beta=0.042, p=0.675$ ) relation with the ATD. This implies that AI are necessary for improved ATD, hence, for fuel efficiency. In addition, AI had a significant positive ( $\beta=0.609, p>0.01)$ effect on AO. This means that AI developments are very important for fuel efficient aircraft operations.

The moderating effect of industry type (academic, aviation) on SEP and ATD was also found to be positive and significant (academic $=0.268$, aviation $=0.515, \Delta Z$ score $=3.57$, $p<0.01$ ). The effect of SEP on ATD was stronger for aviation respondents than the academic respondents. This implies that the aviation respondents are well aware of the fuel efficiency aspects than the academics respondents. Also, this supports the validity of our FEAT model. Therefore, different levels of working environment will produce markedly different results in different modelling perspectives. In addition, The moderating effect of experience (low, high) on SEP and AO was also found to be positive and significant (low experienced $=0.380$, high experienced $=0.618, \Delta$ Zscore $=2.437, p<0.01$ ). The effect of SEP on AO was stronger for more experienced respondents than the low experienced respondents. Nonetheless, it is important to consider both experience levels since this makes it possible to identify the difference between the moderation effects on the direct relationship between SEP and AO. After grouping the users according to their level of experience, in each group there should be respondents with both high and low experience. Nevertheless, when users are divided according to their level of aviation research experience, it is necessary to consider a source of bias - those users with high aviation research experience will have a more clear, and enduring attitude towards FEAT improvement.

We did not find clear support for the hypothesis on the twoway interaction between SEP and AFP on ATD. We also did not find evidence for our hypothesis on the two-way interaction of SEP and AI on AO. This implies that high SEP measures put pressure on airlines for fuel efficiency improvement; so optimum SEP measures are necessary. Since fuel efficiency is primarily evaluated by factors such as ATD and AO, policy makers and transportation researchers need to focus on changing the built environment in a way that does not promote extreme SEP measures.

This study, however, had one major limitation which must be noted. One is common to all survey research: a possible self reporting bias: some of the variables were self-reported. Future studies can also include some of the variables which were not included in this study, such as aircraft size, wing span, tail areas, engine fan pressure ratio, engine turbine inlet temperature, initial cruise altitude, final cruise altitude, community awareness, viscosity, and storage stability. Furthermore, around $56 \%$ of samples have drawn from aviation firms, in the future, the sample size of airline industry insiders can be improved for more aviation industry specific model of ERP. The finding of the study will help aircraft manufacturer \& airlines to frame their criteria regarding fuel efficiency improvement in air transport. The air transport sector can also prioritize the criteria on which they should focus in order to improve their performance. Finally, for improving the fuel efficiency from aviation the policy makers should focus on five dimensions \& their relationship. Also, they should encourage for continued investment in airframe and engine technology. Furthermore, the policy makers should introduce appropriate policies and incentives for sustainable alternative fuels, improved air traffic management and airport infrastructure, and more efficient operations of aircraft.

\section{Appendix}

Table 10 Description of FEAT decision variables

\begin{tabular}{ll}
\hline Decision variables & Description of decision variables \\
\hline ATD1 & Thrust specific fuel consumption \\
ATD2 & Lift/drag ratio \\
ATD3 & Operating empty weight \\
ATD4 & Maximum takeoff weight \\
AO1 & Takeoff filed length \\
AO2 & Aircraft range \\
AO3 & Fuel weight \\
AO4 & Payload, \\
AO5 & Aircraft speed \\
AO6 & Crew weight \\
AO7 & Reserve fuel weight \\
AO8 & Landing filed length \\
AFP1 & Fuel availability \\
AFP2 & Net calorific value \\
AFP3 & Energy density \\
AFP4 & Aromatic content, \\
AFP5 & Carbon content, \\
AFP6 & Thermal stability \\
AFP7 & Flash point \\
SEP1 & Social demand \\
SEP2 & Fuel cost \\
SEP3 & Voluntary measures \\
SEP4 & Demand shift \\
SEP5 & Passenger load factor \\
SEP6 & Charging carbon emission, and \\
SEP7 & Taxing aviation fuel \\
AI1 & Origin airport \\
AI2 & Destination airport \\
AI3 & Flight profile \\
AI4 & Runway design \\
AI5 & Taxiway \\
AI6 & Apron \\
AI7 & Weather conditions \\
\hline & \\
\hline
\end{tabular}




\section{Survey instrument of FEAT study}

Part 1: Respondents demographic information

\begin{tabular}{|c|c|c|c|c|}
\hline 1. & Gender & Male- & Female- $\square$ & \\
\hline 2. & Age (Years) & $\begin{array}{ll}24-34 & -\square \\
35-44 & -\square\end{array}$ & $45-54-$ & 55 and Above - $\square$ \\
\hline 3. & Education level & Graduation - $\square$ & Post-graduation- $\square$ & Doctorate- \\
\hline 4. & Industry type & Academics - $\square$ & Aviation- & \\
\hline 5. & Experience level & $3-15-\square$ & $16-30-\square$ & 31 and Above - $\square$ \\
\hline 6. & Occupation & $\begin{array}{l}\text { Director- } \square \\
\text { Manager- } \square \\
\text { Research Scientist- } \square\end{array}$ & $\begin{array}{l}\text { Aircraft Pilot- } \square \\
\text { Professor- } \square \\
\text { Associate Professor- } \square\end{array}$ & $\begin{array}{l}\text { Assistant Professor- } \\
\text { Lecturer- } \square \\
\text { Senior Lecturer - } \square\end{array}$ \\
\hline
\end{tabular}


Part 2: Survey questionnaire

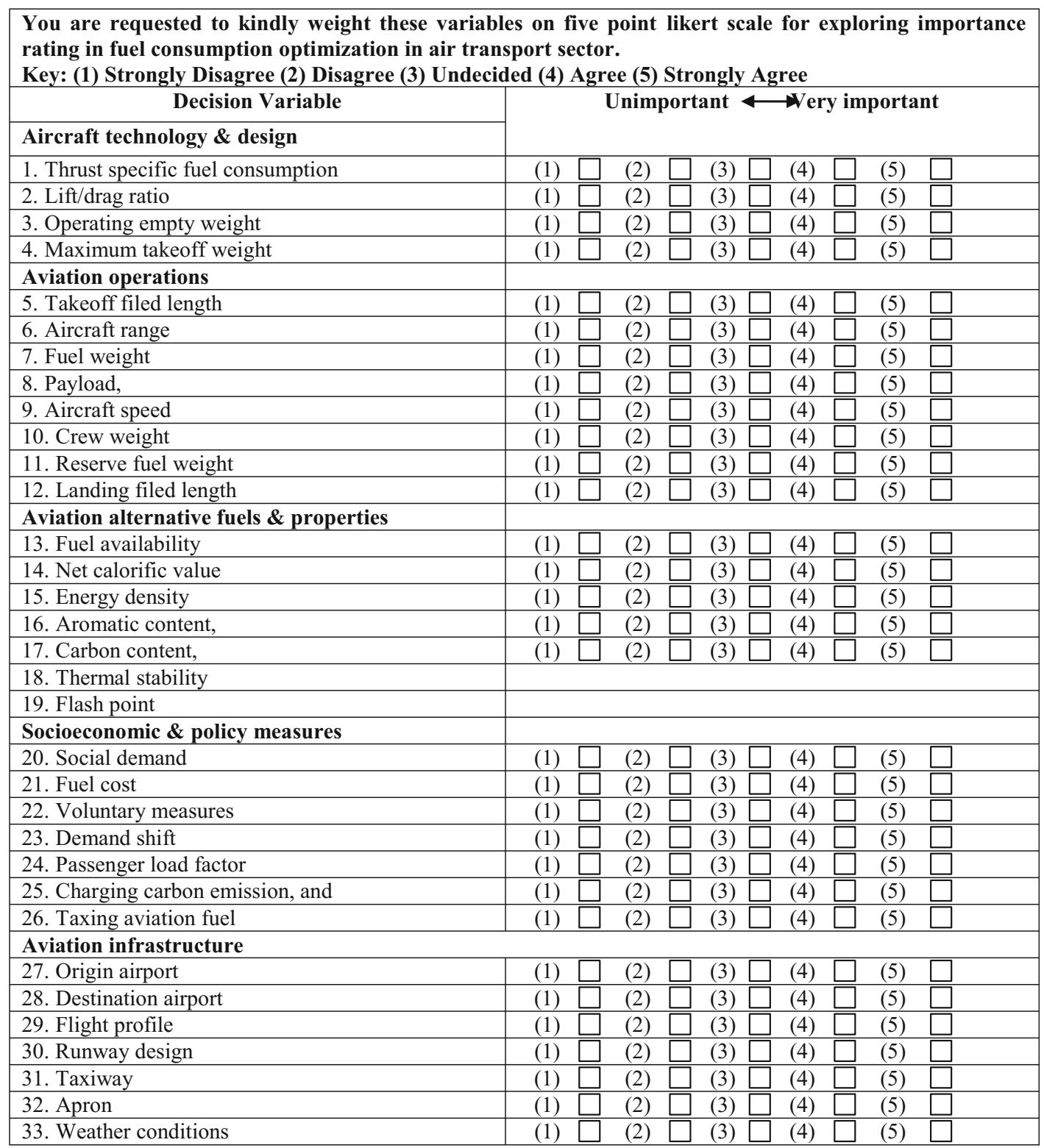


Open Access This article is distributed under the terms of the Creative Commons Attribution 4.0 International License (http:// creativecommons.org/licenses/by/4.0/), which permits unrestricted use, distribution, and reproduction in any medium, provided you give appropriate credit to the original author(s) and the source, provide a link to the Creative Commons license, and indicate if changes were made.

\section{References}

1. Abbas A, de Vicente J, Valero E (2013) Aerodynamic technologies to improve aircraft performance. Aerosp Sci Technol 28(1):100 132. doi:10.1016/j.ast.2012.10.008

2. Abdelghany K, Abdelghany A, Raina S (2005) A model for the airlines' fuel management strategies. J Air Transp Manag 11(4): 199-206. doi:10.1016/j.jairtraman.2004.10.002

3. Akamavi R, Mohamed E, Pellmann K, Xu Y (2015) Key determinants of passenger loyalty in the low-cost airline business. Tour Manag 46:528-545. doi:10.1016/j.tourman. 2014.07.010

4. Babikian R, Lukachko S, Waitz I (2002) The historical fuel efficiency characteristics of regional aircraft from technological, operational, and cost perspectives. J Air Transp Manag 8(6):389-400. doi:10.1016/s0969-6997(02)00020-0

5. Baklacioglu T (2016) Modeling the fuel flow-rate of transport aircraft during flight phases using genetic algorithm-optimized neural networks. Aerosp Sci Technol 49:52-62. doi:10.1016/j.ast.2015. 11.031

6. Bezerra G, Gomes C (2015) The effects of service quality dimensions and passenger characteristics on passenger's overall satisfaction with an airport. J Air Transp Manag 44-45:77-81. doi:10. 1016/j.jairtraman.2015.03.001

7. Braun-Unkhoff M, Riedel U (2014) Alternative fuels in aviation. CEAS Aeronaut J 6(1):83-93. doi:10.1007/s13272014-0131-2

8. Braun-Unkhoff M, Kathrotia T, Rauch B, Riedel U (2015) About the interaction between composition and performance of alternative jet fuels. CEAS Aeronaut J. doi:10.1007/ s13272-015-0178-8

9. Brueckner J, Zhang A (2010) Airline emission charges: effects on airfares, service quality, and aircraft design. Transp Res B Methodol 44(8-9):960-971. doi:10.1016/j.trb.2010.02. 006

10. Byrne B (2010) Structural equation modeling with AMOS. Routledge, Taylor \& Francis Group, New York

11. Byrne, B. M. (2013). Structural equation modeling with AMOS: basic concepts, applications, and programming. Routledge, Taylor \& Francis

12. Carlsson $\mathrm{F}$, Hammar $\mathrm{H}$ (2002) Incentive-based regulation of $\mathrm{CO}_{2}$ emissions from international aviation. J Air Transp Manag 8(6): 365-372. doi:10.1016/s0969-6997(02)00011-x

13. Chandra S, Chitgopeker C, Crawford B, Dwyer J, Gao Y (2014) Establishing a benchmark of fuel efficiency for commercial airline operations. J Aviat Technol Eng 4(1). doi:10. 7771/2159-6670.1097

14. Chang Y (2012) Cabin safety behavioral intentions of passengers with reduced mobility. J Air Transp Manag 25:64-66. doi:10.1016/ j.jairtraman.2012.08.010

15. Chao C, Chen H, Yeh T (2015) A comprehensive relationship marketing model between airlines and travel agencies: the case of Taiwan. J Air Transp Manag 47:20-31. doi:10.1016/j.jairtraman. 2015.03.015
16. Chen F (2013) The intention and determining factors for airline passengers' participation in carbon offset schemes. J Air Transp Manag 29:17-22. doi:10.1016/j.jairtraman.2013.01.001

17. Chen C, Kao Y (2011) The antecedents and consequences of job stress of flight attendants - Evidence from Taiwan. J Air Transp Manag 17(4):253-255. doi:10.1016/j.jairtraman.2011.01.002

18. Chou P (2015) An analysis of the relationship between service failure, service recovery and loyalty for Low cost carrier travelers. J Air Transp Manag 47:119-125. doi:10.1016/j.jairtraman.2015.05.007

19. Cortina J (1993) What is coefficient alpha? An examination of theory and applications. J Appl Psychol 78(1):98-104. doi:10. 1037//0021-9010.78.1.98

20. Cui Q, Li Y (2015) Evaluating energy efficiency for airlines: an application of VFB-DEA. J Air Transp Manag 44-45:34-41. doi: 10.1016/j.jairtraman.2015.02.008

21. Drela M (2011) Design drivers of energy-efficient transport aircraft. SAE Int J Aerosp 4(2):602-618. doi:10.4271/2011-01-2495

22. Forgas S, Palau R, Sánchez J, Huertas-García R (2012) Online drivers and offline influences related to loyalty to airline websites. J Air Transp Manag 18(1):43-46. doi:10.1016/j.jairtraman.2011. 08.003

23. Fornell C, Larcker D (1981) Evaluating structural equation models with unobservable variables and measurement error. J Mark Res 18(1):39. doi: $10.2307 / 3151312$

24. Graham W, Hall C, Vera Morales M (2014) The potential of future aircraft technology for noise and pollutant emissions reduction. Transp Policy 34:36-51. doi:10.1016/j.tranpol.2014.02.017

25. Green J (2009) The potential for reducing the impact of aviation on climate. Tech Anal Strat Manag 21(1):39-59. doi:10.1080/ 09537320802557269

26. Grote M, Williams I, Preston J (2014) Direct carbon dioxide emissions from civil aircraft. Atmos Environ 95:214-224. doi:10.1016/ j.atmosenv.2014.06.042

27. Guerreiro Fregnani J, Müller C, Correia A (2011) A fuel tankering model applied to a domestic airline network. J Adv Transp 47(4): 386-398. doi:10.1002/atr.162

28. Hair J, Black W, Babin B, Anderson R, Tatham R (2010) Multivariate data analysis, 7th edn. Pearson Prentice Hall, Upper Saddle River

29. Henderson R, Martins J, Perez R (2012) Aircraft conceptual design for optimal environmental performance. Aeronaut J 116(3712):122

30. Henson R (2006) Use of exploratory factor analysis in published research: common errors and some comment on improved practice. Educ Psychol Meas 66(3):393-416. doi:10.1177/ 0013164405282485

31. Hihara K (2011) Analysis on bargaining about global climate change mitigation in international aviation sector. Transp Res E: Logist Transp Rev 47(3):342-358. doi:10.1016/j.tre.2010. 11.006

32. Hileman J, De la Rosa Blanco E, Bonnefoy P, Carter N (2013) The carbon dioxide challenge facing aviation. Prog Aerosp Sci 63:84 95. doi:10.1016/j.paerosci.2013.07.003

33. Hileman J, Stratton R (2014) Alternative jet fuel feasibility. Transp Policy 34:52-62. doi:10.1016/j.tranpol.2014.02.018

34. Hsu Y, Liu T (2012) Structuring risk factors related to airline cabin safety. J Air Transp Manag 20:54-56. doi:10.1016/j.jairtraman. 2011.12.009

35. Hu L, Bentler P (1999) Cutoff criteria for fit indexes in covariance structure analysis: conventional criteria versus new alternatives. Struct Equ Model: Multidiscip J 6(1):1-55. doi:10.1080/ 10705519909540118

36. IATA, Annual Review (2015) Retrieved from https://www.iata.org/ about/Documents/iata-annual-review-2015.pdf

37. IATA, Technology Roadmap Report (2013) Retrieved from http:// www.iata.org/publications/Pages/technology-roadmap.aspx 
38. ICAO, Environmental Report (2013) Retrieved from http://cfapp. icao.int/Environmental-Report-2013/

39. Ismail N, Jenatabadi H (2014) The influence of firm age on the relationships of airline performance, economic situation and internal operation. Transp Res A Policy Pract 67:212-224. doi:10.1016/ j.tra.2014.06.010

40. Janic M (2010) Is liquid hydrogen a solution for mitigating air pollution by airports? Int J Hydrog Energy 35(5):2190-2202. doi: 10.1016/j.jijhydene.2009.12.022

41. Janić M (2014) Greening commercial air transportation by using liquid hydrogen (LH2) as a fuel. Int J Hydrog Energy 39(29): 16426-16441. doi:10.1016/j.ijhydene.2014.08.011

42. Jenatabadi H, Ismail N (2014) Application of structural equation modelling for estimating airline performance. J Air Transp Manag 40:25-33. doi:10.1016/j.jairtraman.2014.05.005

43. Jöreskog K, Sörbom D (1993) LISREL 8. Scientific Software International, Chicago

44. Kaiser H (1974) An index of factorial simplicity. Psychometrika 39(1):31-36

45. Kazda A, Caves R (2007) Airport design and operation. Elsevier, Amsterdam

46. Keen M, Parry I, Strand J (2013) Planes, ships and taxes: charging for international aviation and maritime emissions. Econ Policy 28(76):701-749. doi:10.1111/1468-0327.12019

47. Kim S (2008) Moderating effects of job relevance and experience on mobile wireless technology acceptance: adoption of a smartphone by individuals. Inf Manag 45(6):387-393. doi:10. 1016/j.im.2008.05.002

48. Kuo C, Jou R (2014) Asymmetric response model for evaluating airline service quality: an empirical study in cross-strait direct flights. Transp Res A Policy Pract 62:63-70. doi:10.1016/j.tra. 2014.02.004

49. Lai W, Chen C (2011) Behavioral intentions of public transit passengers - The roles of service quality, perceived value, satisfaction and involvement. Transp Policy 18(2):318-325. doi:10.1016/j. tranpol.2010.09.003

50. Lee J (2010) Can we accelerate the improvement of energy efficiency in aircraft systems? Energy Convers Manag 51(1):189-196. doi: 10.1016/j.enconman.2009.09.011

51. Lee J, Lukachko S, Waitz I, Schafer A (2001) Historical and future trends in aircraft performance, cost, and emissions. Annu Rev Energy Environ 26(11):167-200

52. Lee J, Mo J (2011) Analysis of technological innovation and environmental performance improvement in aviation sector. Int $\mathrm{J}$ Environ Res Public Health 8(9):3777-3795. doi:10.3390/ ijerph8093777

53. Li Y, Wang Y, Cui Q (2016) Energy efficiency measures for airlines: an application of virtual frontier dynamic range adjusted measure. J Renewable Sustainable Energy 8(1):015901. doi:10.1063/1. 4938221

54. Mikulić J, Prebežac D (2011) What drives passenger loyalty to traditional and low-cost airlines? A formative partial least squares approach. J Air Transp Manag 17(4):237-240. doi:10.1016/j. jairtraman.2010.09.005

55. Miyoshi C, Ibáñez E (2016) Are fuel-efficient aircraft worth investing in for non-Annex country airlines? An empirical analysis of Kenya Airways with an aircraft appraisal cost-benefit analysis model. Transp Policy 47:41-54. doi:10.1016/j.tranpol.2015.12.005

56. Morrell P (2009) The potential for European aviation CO2 emissions reduction through the use of larger jet aircraft. J Air Transp Manag 15(4):151-157. doi:10.1016/j.jairtraman.2008.09.021

57. Ng S, Sambasivan M, Zubaidah S (2011) Antecedents and outcomes of flight attendants' job satisfaction. J Air Transp Manag 17(5):309-313. doi:10.1016/j.jairtraman.2011.03.007

58. Nojoumi H, Dincer I, Naterer G (2009) Greenhouse gas emissions assessment of hydrogen and kerosene-fueled aircraft propulsion. Int
J Hydrog Energy 34(3):1363-1369. doi:10.1016/j.jhydene.2008. 11.017

59. Norman G, Streiner D (2008) Biostatistics. B.C. Decker, Hamilton

60. Nunnally J (1978) Psychometric theory. McGraw-Hill, New York

61. Parker R (2009) From blue skies to green skies: engine technology to reduce the climate-change impacts of aviation. Tech Anal Strat Manag 21(1):61-78. doi:10.1080/ 09537320802557301

62. Peeters P, Middel J, Hoolhorts A (2005) Fuel efficiency of commercial aircraft: an overview of historical and future trends. National Aerospace Laboratory NLR, Amsterdam, pp 1-37

63. Penner J (1999) Aviation and the global atmosphere. Cambridge University Press, Cambridge

64. Podsakoff P, MacKenzie S, Lee J, Podsakoff N (2003) Common method biases in behavioral research: a critical review of the literature and recommended remedies. J Appl Psychol 88(5):879-903. doi:10.1037/0021-9010.88.5.879

65. Ryerson M, Hansen M, Bonn J (2014) Time to burn: Flight delay, terminal efficiency, and fuel consumption in the National Airspace System. Transp Res A Policy Pract 69:286-298. doi:10.1016/j.tra. 2014.08.024

66. Salah K (2013) Environmental impact reduction of commercial aircraft around airports. Less noise and less fuel consumption. Eur Transp Res Rev 6(1):71-84. doi:10.1007/s12544-013-0106-0

67. Senzig D, Fleming G, Iovinelli R (2009) Modeling of terminal-area airplane fuel consumption. J Aircr 46(4):1089-1093. doi:10.2514/ 1.42025

68. Sgouridis S, Bonnefoy P, Hansman R (2011) Air transportation in a carbon constrained world: long-term dynamics of policies and strategies for mitigating the carbon footprint of commercial aviation. Transp Res A Policy Pract 45(10):1077-1091. doi:10.1016/j.tra. 2010.03.019

69. Sheu J (2014) Airline ambidextrous competition under an emissions trading scheme $-\mathrm{A}$ reference-dependent behavioral perspective. Transp Res B Methodol 60:115-145. doi:10.1016/j.trb.2013. 12.008

70. Siemsen E, Roth A, Oliveira P (2009) Common method bias in regression models with linear, quadratic, and interaction effects. Organ Res Methods 13(3):456-476. doi:10.1177/ 1094428109351241

71. Simaiakis I, Khadilkar H, Balakrishnan H, Reynolds T, Hansman R (2014) Demonstration of reduced airport congestion through pushback rate control. Transp Res A Policy Pract 66:251-267. doi:10.1016/j.tra.2014.05.014

72. Simoes A, Schaeffer R (2005) The Brazilian air transportation sector in the context of global climate change: $\mathrm{CO} 2$ emissions and mitigation alternatives. Energy Convers Manag 46(4):501-513. doi:10.1016/j.enconman.2004.06.017

73. Singh V, Sharma S (2014) Evolving base for the fuel consumption optimization in Indian air transport: application of structural equation modeling. Eur Transp Res Rev 6(3):315-332. doi:10.1007/ s12544-014-0134-4

74. Singh V, Sharma S (2015) Fuel consumption optimization in air transport: a review, classification, critique, simple meta-analysis, and future research implications. Eur Transp Res Rev 7(2). doi: 10.1007/s12544-015-0160-x

75. Suki N (2014) Passenger satisfaction with airline service quality in Malaysia: a structural equation modeling approach. Res Transp Bus Manag 10:26-32. doi:10.1016/j. rtbm.2014.04.001

76. Timmis A, Hodzic A, Koh L, Bonner M, Soutis C, Schäfer A, Dray L (2014) Environmental impact assessment of aviation emission reduction through the implementation of composite materials. Int J Life Cycle Assess 20(2):233-243. doi:10.1007/s11367-0140824-0 
77. Upham P, Thomas C, Gillingwater D, Raper D (2003) Environmental capacity and airport operations: current issues and future prospects. J Air Transp Manag 9(3):145-151. doi:10.1016/ s0969-6997(02)00078-9

78. Williams, V. (2007). The engineering options for mitigating the climate impacts of aviation. Philosophical Transactions of the Royal Society of London A: Mathematical, Physical and Engineering Sciences 365(1861):3047-3059

79. Williams L, Edwards J, Vandenberg R (2003) Recent advances in causal modeling methods for organizational and management research. J Manag 29(6):903-936. doi:10.1016/s0149-2063_03_ 00084-9
80. Yamaguchi K (2010) Voluntary CO2 emissions reduction scheme: analysis of airline voluntary plan in Japan. Transp Res Part D: Transp Environ 15(1):46-50. doi:10.1016/j.trd.2009.07.004

81. Yeh Y (2014) Exploring the impacts of employee advocacy on job satisfaction and organizational commitment: case of Taiwanese airlines. J Air Transp Manag 36:94-100. doi:10.1016/j.jairtraman. 2014.01.002

82. Zhang Y (2014) Special issue: aviation alternative fuels. Aerospace 1(3):100. doi:10.3390/aerospace 1030100

83. Zou B, Elke M, Hansen M, Kafle N (2014) Evaluating air carrier fuel efficiency in the US airline industry. Transp Res A Policy Pract 59:306-330. doi:10.1016/j.tra.2013.12.003 